\title{
Kinetics and isothermal modeling of liquid phase adsorption of rhodamine B onto urea modified Raphia hookerie epicarp
}

\author{
A. A. Inyinbor ${ }^{1}$ - F. A. Adekola ${ }^{2}$ G. A. Olatunji ${ }^{2}$
}

Received: 30 March 2016/Accepted: 1 September 2016/Published online: 14 September 2016

(C) The Author(s) 2016. This article is published with open access at Springerlink.com

\begin{abstract}
Epicarp of Raphia hookerie, a bioresource material, was modified with urea (UMRH) to adsorb Rhodamine B (RhB) from aqueous solution. Adsorbent morphology and surface chemistry were established by Brunauer-Emmett-Teller (BET) surface area determination, Fourier transform infrared spectroscopic (FTIR) analysis, scanning electron microscopy (SEM), as well as the $\mathrm{pH}$ point of zero charge (pHpzc) determination. Prepared material was subsequently utilized for the uptake of Rhodamine B (RhB). Operational parameters, such as adsorbent dosage, concentration, time, and temperature, were investigated. Evidence of effective urea modification was confirmed by vivid absorption bands at 1670 and $1472 \mathrm{~cm}^{-1}$ corresponding to $\mathrm{C}=\mathrm{O}$ and $\mathrm{C}-\mathrm{N}$ stretching vibrations, respectively. Optimum adsorption was obtained at $\mathrm{pH}$ 3. Freundlich adsorption isotherm best fits the equilibrium adsorption data, while evidence of adsorbateadsorbate interaction was revealed by Temkin isotherm model. The maximum monolayer adsorption capacity $\left(q_{\max }\right)$ was $434.78 \mathrm{mg} / \mathrm{g}$. Kinetics of the adsorption process was best described by the pseudo-second-order kinetics model. Desorption efficiency was less than or equal to $25 \%$ for all the eluents, and it follows the order $\mathrm{HCl}>\mathrm{H}_{2} \mathrm{O}>\mathrm{CH}_{3} \mathrm{COOH}$.
\end{abstract}

Keywords Raphia hookerie - Biomass - Rhodamine B . Kinetics

A. A. Inyinbor

inyinbor.adejumoke@1andmarkuniversity.edu.ng

1 Department of Physical Sciences, Landmark University, Omu Aran P.M.B 1001, Nigeria

2 Department of Industrial Chemistry, University of Ilorin, Ilorin P.M.B 1515, Nigeria

\section{Introduction}

Rhodamine $\mathrm{B}(\mathrm{RhB})$ is a xanthenes dye characterized by high solubility in water, easy wet fastness, and fluorescence. Its unique characteristics gave it wide application potentials in dyeing of textile, paper, paint, and leathers, aside being used as a water tracer and biological stain ( $\mathrm{Li}$ et al. 2010; Huang et al. 2016). RhB is a known carcinogen, and it causes eyes, skin, and respiratory tract irritations (Bhattacharyya et al. 2014). It increases hypothalamic cell apoptosis, as well as causes the disruption of hormonal balance (Sulistina et al. 2014). RhB laden effluents, therefore, require effective treatment before their final disposal.

Adsorption of pollutants from wastewater using activated carbon has been widely accepted due to its simplicity of operation, and ability to remove very low concentration of pollutants from wastewater (Khan et al. 2014a; Santos et al. 2015). Pyrolysis of organic materials, followed by activation via physical or chemical methods, produces activated carbon. They are characterized by large surface areas ranging between 600 and $2000 \mathrm{~m}^{2} / \mathrm{g}$, and very porous structure (DuyguOzsoy and Van Leeuwen 2010; Bhatnagar and Sillanpaa 2010). While activated carbon remains attractive due to the various aforementioned advantages, the economic disadvantage stemming from its raw material and processing procedure makes environmentalists seek alternatives.

Naturally occurring materials, in their raw as well as modified forms, were reported as effective adsorbents in dye removal (Khan et al. 2013, 2015; Inyinbor et al. 2016). These materials possessing low inorganic contents, high carbon contents, as well as various functional groups have high affinity for pollutants uptakes. For instance, agricultural wastes containing cellulose, hemicellulose, as well as 
lignin have served as excellent materials in the adsorption of pollutants, such as heavy metals and dyes (Miretzky and Cirelli 2010). Utilizing agro wastes as low-cost adsorbent for pollution control presents economic and environmental protection advantages. Hence, materials that would have been of no value have found relevant use. While raw biomass may be utilized for the uptake of various pollutants, its efficiency may be further enhanced via modification (Khan et al. 2014b).

Specific functional groups in dye molecules encourage addition or substitution reactions with the $-\mathrm{OH},-\mathrm{SH}$ or $\mathrm{NH}_{2}$ groups present in textile fibers (Rego and Ferreira 2001). Functionalization of biomaterials with chemicals containing amino groups should enhance the adsorption potential of such biomaterial, as well as present an adsorbent with specific function.

Raphia hookerie (RH) belongs to the Palmicea family, and has great potentials for pollutants uptake. Its neglect, viz-a-viz environmental remediation, is, therefore, a concern. We previously reported the use of raw Raphia hookerie ( $\mathrm{RH})$ fruit epicarp in the adsorption of $\mathrm{RhB}$ (Inyinbor et al. 2016a). This study, however, aims at enhancing the adsorption potential of RH by tailoring the surface of this readily available waste towards a specific pollutant (Rhodamine B). Currently, the epicarp of Raphia hookerie has no economical use, and its disposal naturally constitutes nuisance to the environment. RH was modified with urea. The approach of this treatment depends on the possibility of a reaction between the functional group(s) on $\mathrm{RhB}$ and $-\mathrm{NH}_{2}$ (scheme 1). The prepared bioadsorbents were characterized to understand the porosity, morphology, and surface chemistry of the adsorbent. The adsorption potential in the uptake of $\mathrm{RhB}$ was investigated, and various adsorption operational parameters, such as effects of $\mathrm{pH}$, adsorbent dosage, initial adsorbate concentration/contact time, as well as temperature, were fully reported. Kinetics, isotherm, and thermodynamics studies were employed to test the mechanism for RhB adsorption. Studies were also carried out, and reported on regeneration of the spent adsorbent.

\section{Materials and methods}

\section{Biomass collection and pretreatment}

Epicarps of Raphia hookerie were collected from local farmers in Makogi, Edu Local Government Area of Kwara State, Nigeria. They were washed, pulverized, and screened into particles of $150-250 \mu \mathrm{m}$. The pulverized RH was washed, and thereafter, dried over night in an oven controlled at $353 \mathrm{~K}$.<smiles>CCN(CC)c1ccc2c(-c3ccccc3C(=O)O)c3ccc(=[N+](CC)CC)cc-3oc2c1</smiles><smiles>[B]NC(=O)c1ccccc1-c1c2ccc(=[N+](CC)CC)cc-2oc2cc(N(CC)CC)ccc12</smiles>

Scheme 1 Proposed reaction between Rhodamine B and UMRH

\section{Preparation of urea modified RH (UMRH)}

To achieve urea modification, a mixture of $\mathrm{RH}$ and urea in a ratio of $1: 2$ by mass was exposed to microwave irradiation $(2450 \mathrm{MHz}$ ) for a total period of $12 \mathrm{~min}$ (Farooq et al. 2010). The jelly like slurry substance obtained was boiled in water for half an hour, filtered while hot and further washed with hot water to remove unreacted urea. The residue was dried in a low-temperature oven and, thereafter, stored in an airtight container.

\section{Adsorbent characterization}

A Micrometric Tristar II surface area and porosity analyzer was employed in the BET surface area and average pore diameter determination. Samples were degassed under vacuum at $363 \mathrm{~K}$ for $1 \mathrm{~h}$, and the temperature was further increased to $473 \mathrm{~K}$ overnight. Surface morphology and elemental composition were determined using a FEIESEM Quanta 200 for SEM and EDX. Functional groups were determined with a Bruker Alpha FTIR spectrometer. The $\mathrm{pH}$ point of zero charge (pHpzc) was done as described in our earlier reported work (Inyinbor et al. 2015). 


\section{Adsorbate preparations}

Rhodamine B was supplied by $\mathrm{BDH}$, and its properties are as listed in Table 1. Stock solution of $1000 \mathrm{mg} / \mathrm{L} \mathrm{RhB}$ was prepared, and the resultant working solutions of lower concentration were prepared by serial dilution of the stock solution.

\section{Batch adsorption studies}

Various adsorption operational parameters may influence adsorption process. Solution $\mathrm{pH}$ describes the Chemistry of particular specie in solution as well as the charge on the surface of the adsorbent. Batch adsorption studies with focus on these adsorption operational parameters, viz., initial solution $\mathrm{pH}$, adsorbent dosage, initial $\mathrm{RhB}$ concentration, and contact time, as well as temperature on the removal of $\mathrm{RhB}$, were carried out. Solution $\mathrm{pH}$ was varied between 2 and 10 by adding $0.1 \mathrm{M} \mathrm{HCl}$ or $0.1 \mathrm{M} \mathrm{NaOH}$ to obtain each desired $\mathrm{pH}$. Adsorbent dosage was varied between 1 and $5 \mathrm{~g} / \mathrm{L}$. Varying initial $\mathrm{RhB}$ concentrations of $50,100,200,300$, and $400 \mathrm{mg} / \mathrm{L}$ was used for the effects of adsorbate concentration and contact time study. Temperature was varied between 303 and $333 \mathrm{~K}$ to understand the effects of temperature on RhB uptake onto UMRH. A $0.1 \mathrm{~g}$ UMRH was added to $100 \mathrm{~cm}^{3} \mathrm{RhB}$ solution of a specific concentration in a $250 \mathrm{~cm}^{3}$ glass conical flask. The flask was corked and, thereafter, agitated in a temperature controlled water bath shaker, operated at $130 \mathrm{rpm}$; for a predetermined time. Separation of unadsorbed dye and spent adsorbent was done by centrifugation, while concentration of unadsorbed dye was determined using a Beckman Coulter Du $730 \mathrm{UV} / \mathrm{Vis}$ spectrophotometer, operated at $554 \mathrm{~nm}$.

Table 1 Properties of Rhodamine B

\begin{tabular}{|c|c|}
\hline Parameters & Values \\
\hline Suggested name & Rhodamine B \\
\hline C.I number & 45170 \\
\hline C.I name & Basic violet 10 \\
\hline Class & Rhodamine \\
\hline$\lambda_{\max }$ & $554 \mathrm{~nm}$ \\
\hline Molecular formular & $\mathrm{C}_{28} \mathrm{H}_{31} \mathrm{~N}_{2} \mathrm{O}_{3} \mathrm{Cl}$ \\
\hline Molecular weight & 479.02 \\
\hline Chemical structure & \\
\hline
\end{tabular}

Quantity of RhB adsorbed and percentage RhB removal

Quantity adsorbed at a given time $t$ was calculated using Eq. 1, and percentage removal was obtained using:

$q_{t}=\frac{\left(C_{i}-C_{t}\right) \times V}{M}$

$\%$ Removal $=\frac{\left(C_{i}-C_{f}\right)}{C_{i}} \times 100$,

where $C_{i}, C_{t}$, and $C_{f}$ are the initial concentration, the concentration of $\mathrm{RhB}$ at time $t$, and final concentration of $\mathrm{RhB}$, respectively. $V$ is the volume of $\mathrm{RhB}$ solution used for the adsorption studies in liter, and $M$ is the weight of the adsorbent in $\mathrm{g}$.

\section{Mathematical modeling}

\section{Isothermal studies}

Equilibrium adsorption data were analyzed using the Langmuir, Freundlich, Temkin, and Dubinin-Radushkevich (D$\mathrm{R})$ adsorption isotherm models. The Langmuir isotherm (Langmuir 1916) assumes a surface with homogeneous binding sites, while the Freundlich isotherm (Freundlich 1906) describes multilayer adsorption. Temkin isotherm (Temkin and Pyzhev 1940) assumes linear rather than logarithm decrease in heat of adsorption, while ignoring extremely low and very high concentration. Last, Dubinin Radushkevich (D-R) model (Dubinin and Radushkevich 1947) gives insight into the biomass porosity, as well as the adsorption energy. These isotherms are expressed by Eqs. 36 , respectively. The dimensionless equilibrium parameters $\left(R_{\mathrm{L}}\right)$, which explains the favorability of adsorption, Polanyi potential $(\varepsilon)$, and the mean energy of adsorption $(E)$, can be obtained by Eqs. 3a, 6a, and 6b, respectively:

$\frac{C_{e}}{q_{e}}=\frac{C_{e}}{q_{\max }}+\frac{1}{q_{\max } K_{L}}$

$R_{L}=\frac{1}{\left(1+K_{L} C_{o}\right)}$

$\log q_{e}=\frac{1}{n} \log C_{e}+\log K_{f}$

$q_{e}=B \ln A+B \ln C_{e}$

$\ln q_{e}=\ln q_{o}-\beta \varepsilon^{2}$

$\varepsilon=R T \ln \left(1+\frac{1}{C_{e}}\right)$

$E=\sqrt{\frac{1}{2 \beta}}$, 
where $C_{\mathrm{e}}$ is the equilibrium concentration of $\mathrm{RhB}$ dye $(\mathrm{mg} /$ L), $q_{\mathrm{e}}$ is the quantity of $\mathrm{RhB}$ dye adsorbed onto the adsorbent at equilibrium ( $\mathrm{mg} / \mathrm{g}), q_{\max }$ is the maximum monolayer adsorption capacity of adsorbent $(\mathrm{mg} / \mathrm{g})$, and $K_{\mathrm{L}}$ is the Langmuir adsorption constant $(\mathrm{L} / \mathrm{mg}) . K_{\mathrm{f}}$ and $n$ are Freundlich constants incorporating the factors affecting the adsorption capacity and adsorption intensity, respectively. $A$ is the Temkin isotherm constant $(\mathrm{L} / \mathrm{g})$, from the value of Temkin constant $B, b(\mathrm{~J} / \mathrm{mol})$ which is a constant related to the heat of absorption can be obtained from the expression $B=R T / b, T$ is the absolute temperature $(\mathrm{K})$, and $R$ is the gas constant $(8.314 \mathrm{~J} / \mathrm{mol} / \mathrm{K})$. The value of adsorption energy $(E)$ obtained from the D-R model further provides information as to whether adsorption process is physical or chemical in nature, $\beta$ which is the activity coefficient helps in obtaining the mean sorption energy $E(\mathrm{~kJ} / \mathrm{mol})$.

\section{Kinetics model}

The kinetic of the adsorption systems were studied using the pseudo-first-order, pseudo-second-order, Elovich, and Avrami kinetics models. The intraparticle diffusion model was used to investigate the mechanism of adsorption process. Equations 7-11 are the linear forms of the pseudofirst-order kinetic model of Lagergren (Lagergren and Svenska 1898), pseudo-second-order kinetic model (Ho and McKay 1999), Elovich (Aharoni and Ungarish 1976), Avrami (Avrami 1940) and the intraparticle diffusion model by Weber and Morris (Weber and Morris 1963), respectively:

$\ln \left(q_{e}-q_{t}\right)=\ln q_{e}-k_{1} t$

$\frac{t}{q_{t}}=\frac{1}{k_{2} q_{e}^{2}}+\frac{t}{q_{e}}$

$q_{t}=\frac{1}{\beta} \beta \ln (\alpha \beta)+\frac{1}{\beta} \ln t$

$\ln [-\ln (1-\alpha)]=n_{A V} K_{A V}+n_{A V} \ln t$

$q_{t}=k_{\mathrm{diff}} t^{1 / 2}+C$

where $q_{\mathrm{e}}$ is the quantity adsorbed at equilibrium $(\mathrm{mg} / \mathrm{g})$ and $q_{t}$ is the quantity absorbed at time $t(\mathrm{mg} / \mathrm{g}) . \alpha$ is a constant related to chemisorption rate and $\beta$ is a constant which depicts the extent of surface coverage. $K_{\mathrm{Av}}$ is the Avrami constant and $n_{\mathrm{Av}}$ is the Avrami model exponent of time related to the change in mechanism of adsorption. $k_{1}, k_{2}$, and $k_{\text {diff }}$ are the rate constant for the pseudo-first-order sorption $\min ^{-1}$, the rate constant of the pseudo-second-order kinetic $\mathrm{g} / \mathrm{mg} \mathrm{min}^{-1}$, and the rate constant for intraparticle diffusion ( $\mathrm{mg} \mathrm{g}^{-1} \min ^{-1 / 2}$ ), respectively. Insight into the thickness of the boundary layer can be obtained from the value of $C$. Large intercept suggests great boundary layer effect.

\section{Validation of adsorption kinetics}

Sum square of error (SSE), Chi-square $\left(X^{2}\right)$, and the normalized standard deviation $\left(\Delta q_{\mathrm{e}} \%\right)$, represented by Eqs. 12-14, were used to validate the kinetics model:

$\mathrm{SSE}=\sum_{i=1}^{n}\left(q_{c a l}-q_{\mathrm{exp}}\right)^{2}$

$X^{2}=\sum_{i=1}^{n} \frac{\left(q_{\exp }-q_{c a l}\right)^{2}}{q_{c a l}}$

$\Delta q_{e}(\%)=100 \sqrt{\left[\frac{\left(q_{\mathrm{exp}}-q_{c a l}\right) / q_{\mathrm{exp}}}{N-1}\right]}$.

\section{Thermodynamic studies}

Thermodynamic parameters that explain feasibility, spontaneity, and the nature of adsorbate-adsorbent interactions $\left(\Delta G^{\mathrm{o}}, \Delta H^{\mathrm{o}}\right.$, and $\Delta S^{\mathrm{o}}$ ) were calculated using the mathematical relations:

$\ln K_{o}=\frac{\Delta S^{\circ}}{R}-\frac{\Delta H^{\circ}}{R T}$

$\Delta G^{o}=-R T \ln K_{o}$,

where $T$ is the temperature in Kelvin, $R$ is the gas constant, and $K_{\mathrm{o}}$ can be obtained from $q_{\mathrm{e}} / C_{\mathrm{e}} . \Delta H^{\mathrm{o}}$ and $\Delta S^{\mathrm{o}}$ can be obtained from the plot of $\ln K_{\mathrm{o}}$ versus $1 / T$.

\section{Spent adsorbent regeneration studies}

To ascertain regeneration and reuse of UMRH, leaching/ desorption of RhB from UMRH surface was investigated using deionized water, $0.1 \mathrm{M} \mathrm{HCl}$ and $0.1 \mathrm{M} \mathrm{CH}_{3}$ $\mathrm{COOH}$. A $0.1 \mathrm{~g}$ of fresh adsorbent was loaded with $\mathrm{RhB}$ by agitating mixture of $0.1 \mathrm{~g}$ and $100 \mathrm{~cm}^{3}$ of $100 \mathrm{mg} / \mathrm{L}$ $\mathrm{RhB}$ solution at $\mathrm{pH} 3.0$ for $1 \mathrm{~h}$. The RhB-loaded adsorbent was separated by centrifugation and the residual $\mathrm{RhB}$ concentration determined spectrophotometrically. To remove the unadsorbed dye, the $\mathrm{RhB}$ loaded adsorbent was gently washed with water, and dried. The desorption process was carried out by mixing $100 \mathrm{~cm}^{3}$ of each desorbing eluent with the dried loadedadsorbent and shaken for a predetermined time, and the desorbed RhB was determined spectrophotometrically. Desorption efficiency was calculated using the mathematical relation:

Desorption efficiency $(\%)=\frac{q_{d e}}{q_{a d}} \times 100$,

where $q_{\mathrm{de}}$ is the quantity desorbed by each of the eluent, and $q_{\text {ad }}$ is the adsorbed quantity during loading. 


\section{Results and discussion}

\section{Characterization of UMRH}

The BET surface area of UMRH was very low. This is a characteristic of lignocellulosic materials (Omorogie et al. 2012; Zhang et al. 2013; Inyinbor et al. 2015a). BET surface area determination of agro waste is usually difficult as the lignocellulosic materials are burnt before degassing temperature is attained. Reducing the degassing temperature subsequently results into the presence of moisture, thus low surface area of the material. The carbon content of UMRH was found to be high (Table 2), thereby making it a suitable material for the uptake of organic pollutants (Wang et al. 2011).

FTIR spectral of RH and UMRH is shown in Fig. 1. For RH, absorption bands were observed at 1029, 1424, and $3297 \mathrm{~cm}^{-1}$ corresponding to $\mathrm{C}-\mathrm{OH}$ stretching vibrations, $\mathrm{CH}_{3}$ bending vibrations, and $\mathrm{O}-\mathrm{H}$ of alcohol, respectively. The absorption band for methylene vibrations occurred at $2934 \mathrm{~cm}^{-1}$ in RH. However, great reduction in the intensities of methylene, $\mathrm{C}-\mathrm{OH}$, and $\mathrm{O}-\mathrm{H}$ vibrations was observed in FTIR spectrum of UMRH. Removal of adventitious water, elimination of volatile compounds, as well as breakdown of hemicellulose may account for such reduction in intensity. New peaks were observed at 1670 and $1472 \mathrm{~cm}^{-1}$. These peaks correspond with $\mathrm{C}=\mathrm{O}$ and $\mathrm{C}-\mathrm{N}$ stretching vibrations, respectively. The two functional groups present in urea are the carbonyl and the amino groups. Vivid appearance of these functional groups in UMRH shows that RH was successfully modified with urea. The new peak at $1472 \mathrm{~cm}^{-1}$ may also indicate that the peak at $3355 \mathrm{~cm}^{-1}$ is a characteristic of absorption band of $\mathrm{N}-\mathrm{H}$ stretching vibrations (Stuart 2004).

Table 2 Characteristics of UMRH

\begin{tabular}{lc}
\hline Parameters & Values \\
& UMRH \\
\hline $\mathrm{pH}$ & 6.18 \\
$\mathrm{pHpzc}$ & 7.60 \\
Bulk density & 0.28 \\
Moisture content $(\%)$ & 8.13 \\
Ash content $(\%)$ & 3.53 \\
BET surface area $\left(\mathrm{m}^{2} / \mathrm{g}\right)$ & $<0.001$ \\
Elemental composition $(\%)$ & \\
Carbon & 70.88 \\
Oxygen & 28.68 \\
Potassium & 0.31 \\
\hline
\end{tabular}

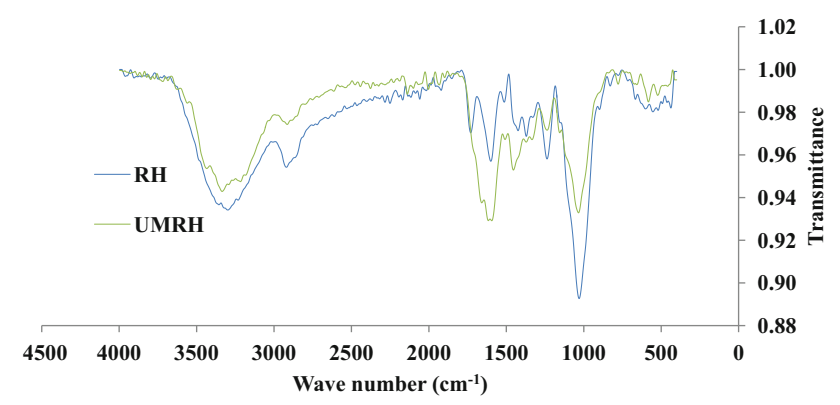

Fig. 1 FTIR spectral of RH and UMRH

Figure $2 \mathrm{a}$ and $\mathrm{b}$ shows the SEM micrograph of $\mathrm{RH}$ and UMRH. Numerous cavities exist on the surface of RH. Microwave irradiation and urea treatment effect, however, left numerous pores on the walls of the cavities. A deep mesopore was also created in the middle of UMRH. Texture of the adsorbent may have been altered by microwave irradiation (Foo and Hameed 2009). Hollows, pores, and cavities are important in solid-liquid adsorption, serving as transport paths for adsorbate movement (Wang et al. 2015). However, after RhB uptake, the smooth surfaces of the adsorbents were observed to be rough, and the visible openings scarcely exist (Fig. 2c).

\section{Adsorption of rhodamine B (RhB) onto UMRH}

\section{Effects of initial adsorbate pH}

The $\mathrm{pH}$ effect is highly important in adsorption studies. The existence of adsorbate in solution, as well as the charge on the adsorbent surface, greatly depends on solution $\mathrm{pH}$. Percentage adsorption increased drastically, as adsorbate solution $\mathrm{pH}$ increased from 2 to 3 . The pHpzc of the adsorbent was in the neutral media with value 7.60. At low $\mathrm{pH}$, adsorbent surface is positively charged, and thus, repulsion between the positive adsorbent surface and cationic form of RhB may result in low adsorption. However, as the $\mathrm{pH}$ increased, the number of positive charge on the adsorbent reduces; hence, percentage adsorption also increases. This phenomenon was obeyed between $\mathrm{pH}$ of 2 and 3. Maximum adsorption of $86.79 \%$ was obtained at $\mathrm{pH} 3$ (Fig. 3). Highest adsorption of $\mathrm{RhB}$ onto the adsorbents at $\mathrm{pH} 3$ may be as a result of diverse existence of $\mathrm{RhB}$ in different solution media. $\mathrm{RhB}$ exists as cationic $\left(\mathrm{RhB}^{+}\right)$at $\mathrm{pH}$ between 1 and 3, lactonic $\left(\mathrm{RhBH}^{2+}\right)$ at $\mathrm{pH}$ of less than 1.0, and zwitterionic $\left(\mathrm{RhB}^{ \pm}\right)$at $\mathrm{pH}$ greater than 3.7. The zwitterionic form of $\mathrm{RhB}$ which occurs at $\mathrm{pH}>3.7$ has the tendency of dimerization, due to attractions between the carboxyl and xanthenes groups of RhB monomers. Hence, 

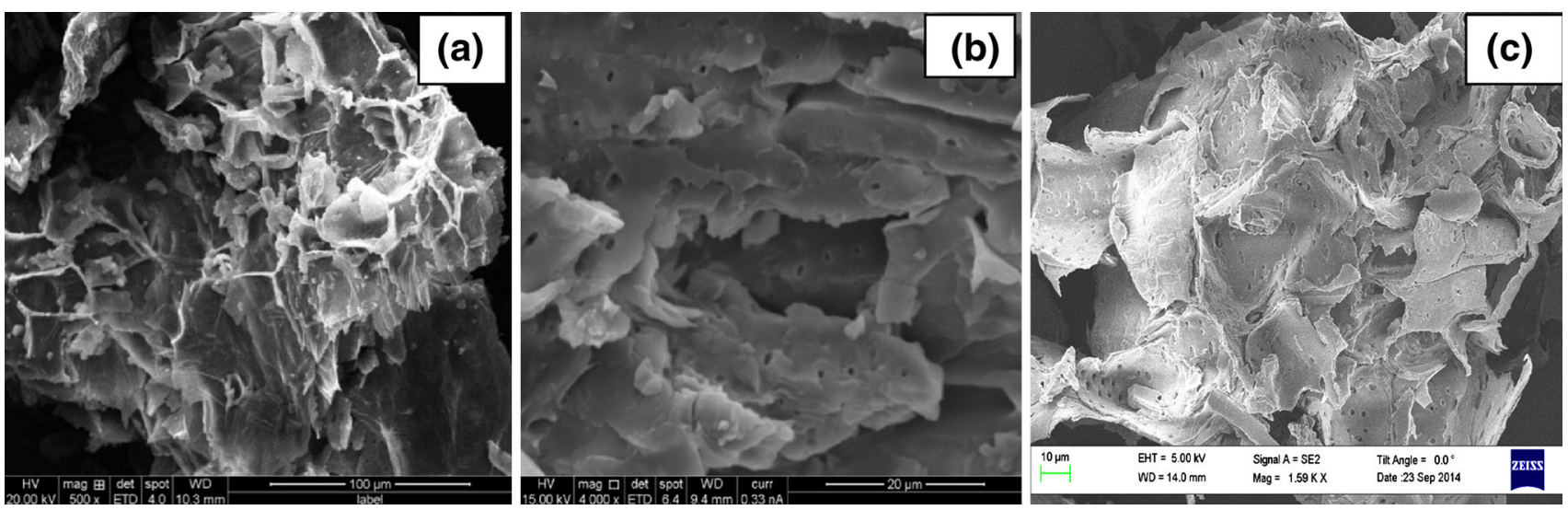

Fig. 2 SEM micrograph of RH (a) UMRH before RhB uptake and (b) after RhB uptake (c)

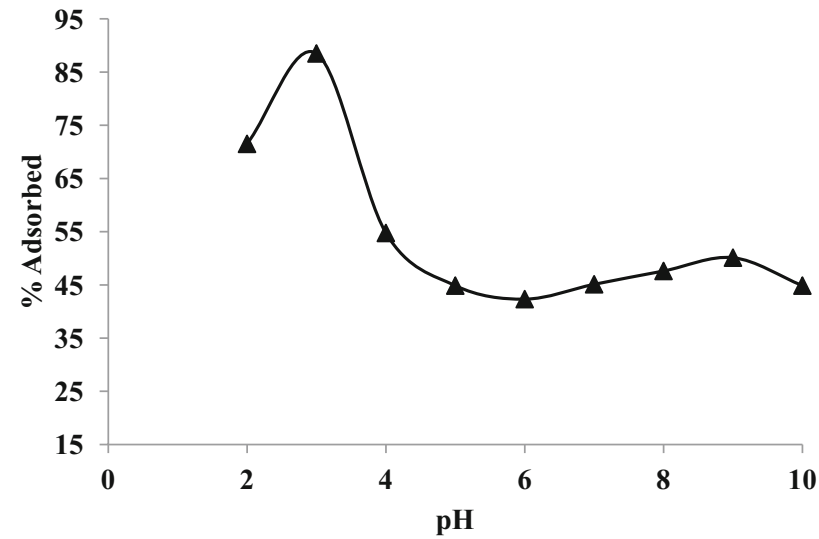

Fig. 3 Effects of pH on RhB adsorption onto UMRH. [dosage $(1 \mathrm{~g} /$ $\mathrm{L})$, agitation speed $(130 \mathrm{rpm})$, agitation time $(60 \mathrm{~min})$, temperature $\left(26^{\circ} \mathrm{C}\right)$, initial adsorbate concentration $\left.(100 \mathrm{mg} / \mathrm{L})\right]$

absorption of $\mathrm{RhB}$ becomes difficult, resulting into decrease in adsorbent adsorption capacity. Maximum adsorption of $\mathrm{RhB}$ at $\mathrm{pH} 3$ has been previously reported by researchers (Inyinbor et al. 2014; Ma et al. 2016; Huang et al. 2016). Subsequent adsorption studies were carried out at optimum $\mathrm{pH}(\mathrm{pH}$ of 3$)$.

\section{Effects of adsorbent dosage}

The effect of adsorbent dosage was carried at a fixed concentration of $100 \mathrm{mg} / \mathrm{L}$ and temperature of $299 \mathrm{~K}$ while varying the adsorbent dosage between 1 and $5 \mathrm{~g} / \mathrm{L}$. There was a rapid increase in percentage $\mathrm{RhB}$ removal from 84.96 to $92.48 \%$, as the adsorbent dosage increased from 1 to $2 \mathrm{~g} / \mathrm{L}$ (Fig. 4). However, no further increase in percentage adsorption was observed after $2 \mathrm{~g} /$ $\mathrm{L}$ dosage, thereby leading to the attainment of equilibrium (Fig. 4). Increase in available adsorption sites as adsorbent dosage increased may have led to increase in percentage RhB removal (Angin 2014). However,

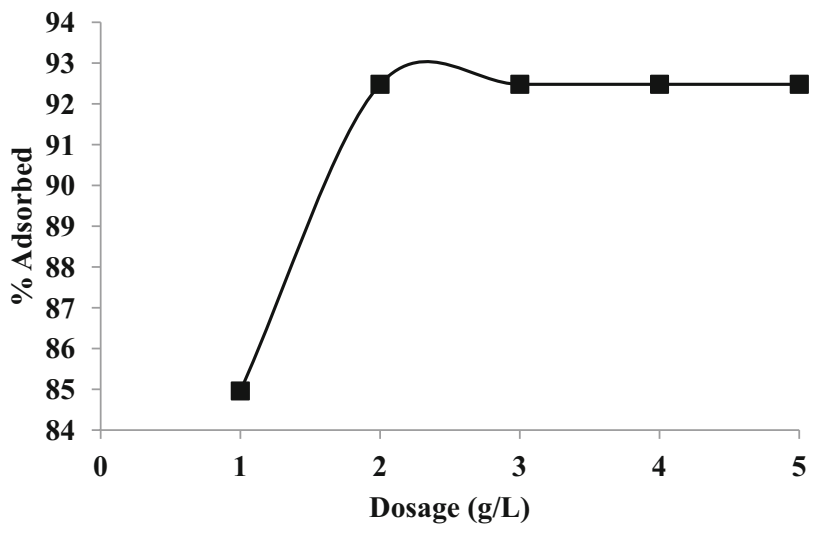

Fig. 4 Effects of adsorbent dosage on RhB adsorption onto UMRH [agitation speed $(130 \mathrm{rpm})$, initial concentration $(100 \mathrm{mg} / \mathrm{L})$, temperature $\left.\left(26^{\circ} \mathrm{C}\right), \mathrm{pH}(3)\right]$

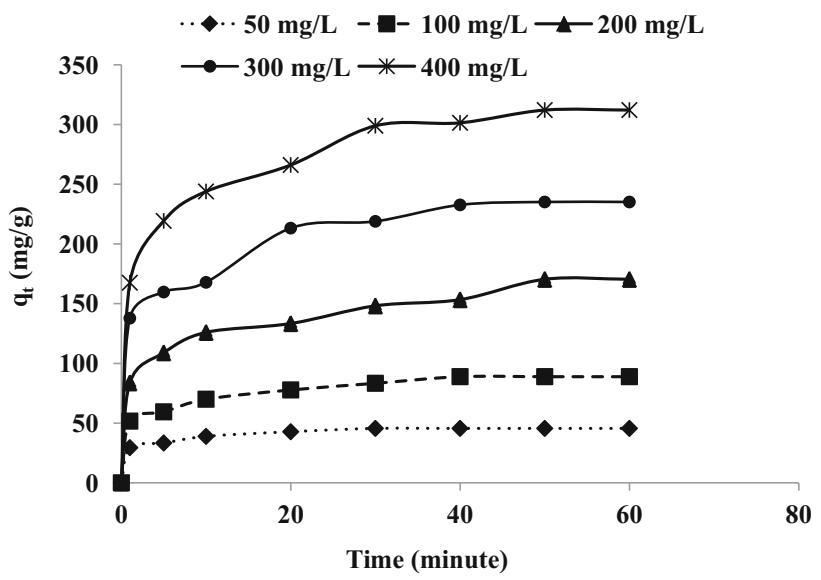

Fig. 5 Effects of concentration/contact time on RhB adsorption onto UMRH [conditions: dosage $=0.1 \mathrm{~g}$, temperature $=26^{\circ} \mathrm{C}$ and agitation speed $=130 \mathrm{rpm}]$

saturation of adsorption site and agglomeration resulted into no further adsorption at higher adsorbent dosage (Pirbazari et al. 2014). 


\section{Effects of contact time and adsorption kinetics}

Quantity of RhB adsorbed increased with time and concentration. Increase in concentration is known to provide an increase in driving force to overcome mass transfer resistance of RhB between the aqueous and solid phases. Adsorption kinetics were fast, and equilibrium was attained after $40 \mathrm{~min}$ (Fig. 5). Quantities adsorbed at equilibrium for various concentrations considered, are listed on Table 3 .

For the pseudo-second-order kinetic, there was close agreement between the calculated quantity adsorbed at equilibrium $\left(q_{\mathrm{cal}}\right)$, and experimentally determined quantity adsorbed at equilibrium $\left(q_{\exp }\right)$, across the initial $\mathrm{RhB}$ concentrations considered (Table 3 ). High correlation coefficient $\left(R^{2}>0.99\right)$ recorded for the pseudo-secondorder kinetics viz-a-viz low values of $X^{2}$, SSE and $\Delta \mathrm{q}(\%)$ suggests a good fitting of adsorption data into this kinetic model. Adsorption data also fitted well into Elovich kinetic models, as $X^{2}$, SSE and $\Delta q(\%)$ were also found to be generally low. Kinetic data fits into the kinetics models in this order: Pseudo-second order $>$ Elovich $>$ Pseudo-first order $>$ Avrami models. A single linear profile was obtained for the intraparticle diffusion plot of UMRH-RhB

Table 3 List of parameters obtained from the pseudo-first-order, pseudo-second-order, Elovich, Avrami, and intraparticle diffusion kinetic model parameters for the adsorption of RhB onto UMRH

\begin{tabular}{|c|c|c|c|c|c|}
\hline \multirow[t]{2}{*}{ Constants } & \multicolumn{5}{|l|}{ UMRH } \\
\hline & 50 & 100 & 200 & 300 & 400 \\
\hline$q_{\mathrm{e}}$ experimental $(\mathrm{mg} / \mathrm{g})$ & 45.56 & 88.9 & 170.37 & 235.14 & 312.11 \\
\hline \multicolumn{6}{|l|}{ Pseudo-first order } \\
\hline$q_{\mathrm{e} \text { calculated }}(\mathrm{mg} / \mathrm{g})$ & 15.62 & 47.39 & 77.69 & 130.63 & 142.71 \\
\hline$K_{1} \times 10^{-2}\left(\min ^{-1}\right)$ & 7.82 & 8.57 & 3.96 & 8.83 & 6.85 \\
\hline$R^{2}$ & 0.9501 & 0.9476 & 0.9673 & 0.9354 & 0.9637 \\
\hline SSE & 896.40 & 1723.08 & 8589.58 & 10922.34 & 28696.36 \\
\hline$X^{2}$ & 57.389 & 36.36 & 110.56 & 83.61 & 201.08 \\
\hline$\Delta q_{\mathrm{e}}(\%)$ & 30.64 & 25.83 & 27.88 & 25.19 & 27.85 \\
\hline \multicolumn{6}{|l|}{ Pseudo-second order } \\
\hline$q_{\mathrm{e} \text { calculated }}(\mathrm{mg} / \mathrm{g})$ & 46.95 & 92.59 & 175.44 & 243.9 & 322.58 \\
\hline$K_{2} \times 10^{-3}\left(\mathrm{~g} \mathrm{mg}^{-1} \mathrm{~min}^{-1}\right)$ & 14.40 & 4.26 & 1.49 & 1.50 & 1.22 \\
\hline$R^{2}$ & 0.9993 & 0.9979 & 0.9908 & 0.9973 & 0.9979 \\
\hline SSE & 1.93 & 13.62 & 25.71 & 76.74 & 109.62 \\
\hline$X^{2}$ & 0.04 & 0.15 & 0.15 & 0.32 & 0.34 \\
\hline$\Delta q_{\mathrm{e}}(\%)$ & 6.60 & 7.70 & 6.52 & 7.29 & 6.92 \\
\hline \multicolumn{6}{|l|}{ Elovich } \\
\hline$\alpha_{\mathrm{El}}(\mathrm{mg} / \mathrm{g} \cdot \min )$ & 2713.05 & 1159.89 & 843.77 & 2913.76 & 3008.97 \\
\hline$\beta_{\mathrm{El}}(\mathrm{g} / \mathrm{mg})$ & 0.22 & 0.09 & 0.05 & 0.04 & 0.03 \\
\hline$R^{2}$ & 0.9550 & 0.9631 & 0.9622 & 0.9288 & 0.9874 \\
\hline SSE & 1.61 & 0.77 & 25.40 & 1.21 & 8.70 \\
\hline$X^{2}$ & 0.03 & 0.01 & 0.15 & 0.01 & 0.03 \\
\hline$\Delta q_{\mathrm{e}}(\%)$ & 6.31 & 3.76 & 6.50 & 2.59 & 3.68 \\
\hline \multicolumn{6}{|l|}{ Avrami } \\
\hline$n_{\mathrm{Av}}$ & 0.32 & 0.33 & 0.33 & 0.41 & 0.40 \\
\hline$K_{\mathrm{av}}\left(\min ^{-1}\right)$ & 0.84 & 0.46 & 0.26 & 0.41 & 0.39 \\
\hline$R^{2}$ & 0.8947 & 0.9172 & 0.9741 & 0.8201 & 0.9345 \\
\hline SSE & 1963.38 & 7707.08 & 28723.47 & 54667.12 & 96621.51 \\
\hline$X^{2}$ & 1570.70 & 6943.32 & 32273.56 & 41103.09 & 76079.93 \\
\hline$\Delta q_{\mathrm{e}}(\%)$ & 37.27 & 37.56 & 37.69 & 37.68 & 37.72 \\
\hline \multicolumn{6}{|l|}{ Intraparticle diffusion } \\
\hline$C \times 10^{2}\left(\mathrm{mg} \mathrm{g}^{-1}\right)$ & 0.13 & 0.26 & 0.52 & 0.99 & 1.33 \\
\hline$K_{\text {diff }}\left(\mathrm{mg} \mathrm{g}^{-1} \min ^{-1 / 2}\right)$ & 2.27 & 5.86 & 11.41 & 15.11 & 21.43 \\
\hline$R^{2}$ & 0.8509 & 0.9488 & 0.9590 & 0.9412 & 0.9455 \\
\hline
\end{tabular}


system and $R^{2}$ value ranged between 0.8509 and 0.9590 . $\beta_{\mathrm{El}}$ which describe the extent of surface coverage was found to decrease with increase in concentration. This further indicates that adsorption process may be described by Elovich model. While boundary layer thickness increased with increase in initial $\mathrm{RhB}$ concentration, intraparticle diffusion rate also behaved in a similar manner. High concentration gradient is generated via increase in initial concentration, thus faster diffusion and quick uptake of adsorbate. The plot of $q_{\mathrm{t}}$ versus $t^{1 / 2}$, however, did not pass through the origin, and thus, intraparticle diffusion is not the rate limiting step.

\section{Equilibrium data and isothermal studies}

The values of $R_{\mathrm{L}}$ and $n$ were found to be less than 1 and greater than 1, respectively, for the adsorption system. This suggests favorable adsorption process. Freundlich adsorption isotherm best describes the uptake of $\mathrm{RhB}$ onto UMRH, suggesting that adsorption of $\mathrm{RhB}$ was not onto a uniform site. A very good correlation coefficient was recorded for the Langmuir, Freundlich, and Temkin adsorption isotherms. The rapid initial adsorption that characterized the $\mathrm{RhB}$ uptake may have followed the Langmuir adsorption type in which RhB removal was based on its interactions with the surface functional groups. Pore penetration, and adsorbate-adsorbate interaction must have resulted to the later gradual $\mathrm{RhB}$ uptake before equilibrium was finally attained. Adsorbate was held to non-uniform sites, and thus, Freundlich isotherm was followed. Temkin isotherm $\left(R^{2}=0.9500\right)$ further validates the occurrence of adsorbate-adsorbate interactions (Bhattacharyya et al. 2014). Judging from the $R^{2}$ values, equilibrium adsorption data fit into isothermal models in this order: Freundlich $>$ Langmuir $>$ Temkin $>$ Dubinin-Radushkevich. The maximum monolayer adsorption capacity obtained are reported in Table 4, and compared with other previously reported literatures (Table 5). Energy of adsorption as obtained from the $\mathrm{D}-\mathrm{R}$ model suggests that chemisorption dominates the uptake of RhB onto UMRH.

\section{Effects of temperature and thermodynamics studies}

Increase in temperature results into activation of more adsorption sites in UMRH, thus resulting into increase in adsorption efficiency of the adsorbents at high temperature. Positive enthalpy $\left(\Delta H^{\circ}\right)$ recorded for UMRH-RhB systems suggests that the adsorption process was endothermic in nature (Table 6). $\Delta S^{\mathrm{o}}$ value for UMRH-RhB systems was positive, thereby suggesting that there was increase in the randomness at the solid-liquid interface during the adsorption of RhB onto UMRH. The randomness at the solid-liquid interface could result from the higher
Table 4 Isotherm constants for the adsorption of RhB onto UMRH

\begin{tabular}{llc}
\hline Isotherms & Constants & UMRH \\
\hline Langmuir & $q_{\text {max }}(\mathrm{mg} / \mathrm{g})$ & 434.78 \\
& $K_{\mathrm{L}}\left(\mathrm{L} \mathrm{mg}^{-1}\right)$ & 0.023 \\
& $R_{\mathrm{L}}$ & 0.0972 \\
& $R^{2}$ & 0.9540 \\
Freundlich & $K_{\mathrm{F}}$ & 18.94 \\
& $n$ & 1.60 \\
Temkin & $R^{2}$ & 0.9923 \\
& $B$ & 84.72 \\
& $A(\mathrm{~L} / \mathrm{g})$ & 0.31 \\
D-R & $b\left(\mathrm{~J} / \mathrm{mol}^{2}\right.$ & 29.44 \\
& $R^{2}$ & 0.9500 \\
& $q_{\mathrm{o}}(\mathrm{mg} / \mathrm{g})$ & 204.04 \\
& $\beta\left(\mathrm{mol}^{2} \mathrm{~kJ}^{-2}\right)$ & 0.0063 \\
& $E\left(\mathrm{~kJ} \mathrm{~mol}^{-1}\right)$ & 8.91 \\
& $R^{2}$ & 0.7800 \\
\hline
\end{tabular}

Table 5 Comparison of the maximum monolayer adsorption capacity $\left(\mathrm{q}_{\max }\right)$ of $\mathrm{RhB}$ onto UMRH with others reported in the literature

\begin{tabular}{lrl}
\hline Adsorbent & $\begin{array}{l}q_{\max } \\
(\mathrm{mg} / \mathrm{g})\end{array}$ & References \\
\hline $\begin{array}{l}\text { Activated pyrolytic tire char } \\
\text { Modified ternary waste }\end{array}$ & $\begin{array}{l}307.20 \\
213.00\end{array}$ & $\begin{array}{l}\text { Li et al. 2010 } \\
\text { Anandkumar and } \\
\text { Mandal 2011 }\end{array}$ \\
Kaolinite & 46.08 & Khan et al. 2012 \\
Fe- supported bentonite & 227.25 & Gao et al. 2015 \\
Modified dika nut & 526.32 & Inyinbor et al. 2015a \\
Carbon residue activated carbon & 189.83 & Maneerung et al. 2016 \\
Fe-montmorillonite & 258.76 & Ma et al. 2016 \\
Lythrum sahcaria activated & 370.37 & Huang et al. 2016 \\
$\quad$ carbon (LSAC) & & \\
Modified LSAC & 384.62 & Huang et al. 2016 \\
Urea modified Raphia hookerie & 434.78 & This study \\
\hline
\end{tabular}

translational entropy acquired by the displaced water molecules, as compared to that lost as a result of dye uptake (Mittal and Mishra 2014). $\Delta G^{\mathrm{o}}$ values obtained were negative (Table 6), suggesting spontaneity of adsorption process. Higher negative values at higher temperature suggest that adsorption process at higher temperature was more spontaneous.

\section{Desorption studies}

Several contacts points between dye molecules and adsorbents usually results into large net adsorption energy, and subsequently low desorption (Fernandez and G.V., Nunell, P.R. Bonelli, and A.L. Cukierman, 2010). In this study, desorption efficiencies of the three eluents were low 
Table 6 Thermodynamic parameters for the uptake of $\mathrm{RhB}$ onto UMRH

\begin{tabular}{lllllll}
\hline Adsorbents & $\begin{array}{l}\Delta H^{\mathrm{o}} \\
(\mathrm{kJ} / \mathrm{mol})\end{array}$ & $\begin{array}{l}\Delta S^{\mathrm{o}} \\
(\mathrm{J} / \mathrm{mol} / \\
\mathrm{K})\end{array}$ & $\begin{array}{l}\Delta G^{\mathrm{o}} \\
(\mathrm{kJ} / \mathrm{mol})\end{array}$ & & & \\
\hline
\end{tabular}

(generally less than $40 \%$ ). This suggests that $\mathrm{RhB}$ was held fast on the surface of the adsorbent. Desorption efficiency follows the order $\mathrm{HCl}>\mathrm{H}_{2} \mathrm{O}>\mathrm{CH}_{3} \mathrm{COOH}$, and it was obtained to be $25,12.50$, and $10.42 \%$ for $\mathrm{HCl}, \mathrm{H}_{2} \mathrm{O}$, and $\mathrm{CH}_{3} \mathrm{COOH}$, respectively.

\section{Conclusion}

Prepared adsorbent was found to be effective in the uptake of RhB. Optimum adsorption was obtained at $\mathrm{pH} 3, \mathrm{RhB}$ percentage removal rose up $92.48 \%$ for adsorbent dosage of $2 \mathrm{~g} / \mathrm{L}$. Multilayer adsorption was vivid for all the adsorption systems, and thus, Freundlich isotherm best describes the adsorption of $\mathrm{RhB}$ onto the adsorbent. However, surface coverage as well as adsorbate-adsorbate interactions also played a predominant role in $\mathrm{RhB}$ uptake onto UMRH. Maximum monolayer adsorption capacity was $434.78 \mathrm{mg} / \mathrm{g}$. Pseudo-second-order kinetics and Elovich model best described the adsorption process, and the adsorption process was spontaneous, feasible, and endothermic.

Acknowledgments The authors gratefully acknowledge the efforts of Miss Fola Funke Oyinloye for the language editing of our manuscript.

Open Access This article is distributed under the terms of the Creative Commons Attribution 4.0 International License (http:// creativecommons.org/licenses/by/4.0/), which permits unrestricted use, distribution, and reproduction in any medium, provided you give appropriate credit to the original author(s) and the source, provide a link to the Creative Commons license, and indicate if changes were made.

\section{References}

Aharoni C, Ungarish M (1976) Kinetics of activated chemisorptions. Part I: the non-Elovichian part of the isotherm. J Chem Soc Faraday Trans 72:265-268

Anandkumar J, Mandal B (2011) Adsorption of Chromium (VI) and Rhodamine $\mathrm{B}$ by surface modified tannery waste: kinetics, mechanistics and thermodynamics. J Hazard Mater 186(2-3):1088-1096

Angin D (2014) Utilization of activated carbon produced from fruit juice industry solid waste for the adsorption of Yellow 18 from aqueous solutions. Bioresour Technol 168:259-266
Avrami M (1940) Kinetics of phase change: transformation-time relations for random distribution of nuclei. J Chem Phys $8: 212-224$

Bhatnagar A, Sillanpaa M (2010) Utilization of agro-industrial and municipal waste materials as potential adsorbents for water treatment-A review. Chem Eng J 157:277-296

Bhattacharyya KG, SenGupta S, Sarma GK (2014) Interactions of the dye, Rhodamine B with kaolinite and montmorillonite in water. Appl Clay Sci 99:7-17

Dubinin MM, Radushkevich LV (1947) Equation of the characteristic curve of activated charcoal. Proc Acad Sci Phys Chem USSR 55:331-333

DuyguOzsoy H, Van Leeuwen J (2010) Removal of color from fruit candy waste by activated carbon adsorption. J Food Eng 101:106-112

Farooq U, Khan MA, Athar M, Sakina M, Ahmad M (2010) Environmentally benign urea-modifed triticum aestivum biomass for lead (II) elimination from aqueous solutions. CleanSoil Water Air 38(1):49-56

Fernandez ME, Nunell GV, Bonelli PR, Cukierman AL (2010) Effectiveness of Cupressus sempervirens cones as biosorbent for the removal of basic dyes from aqueous solutions in batch and dynamic modes. Bioresour Technol 101:9500-9507

Foo KY, Hameed BH (2009) Recent developments in the preparation and regeneration of activated carbons by microwaves. Adv Colloid Interface Sci 149:19-27

Freundlich HMF (1906) Over the adsorption in solution. Z Phys Chem 57:385-470

Gao Y, Wanga Y, Zhang H (2015) Removal of RhodamineB with Fesupported bentonite as heterogeneous photo-Fenton catalyst under visible irradiation. Appl Catal B 178:29-36

Ho YS, McKay G (1999) Pseudo-second order model for sorption processes. Process Biochem 34:451-465

Huang Y, Zheng X, Feng S, Guo Z, Liang S (2016) Enhancement of rhodamine $\mathrm{B}$ removal by modifying activated carbondeveloped from Lythrum salicaria L. with pyruvic acid. Colloids Surf A physicochem Eng Asp 489:154-162

Inyinbor AA, Adekola FA, Olatunji GA (2014) Adsorption of Rhodamine B from aqueous effluent using treated epicarp of Raphia hookerie. Covenant Univ J Phys Life Sci (CJPL) 2(2):83-101

Inyinbor AA, Adekola FA, Olatunji GA (2015a) Adsorption of rhodamine B dye from aqueous solution on Irvingia gabonensis biomass: kinetics and thermodynamics studies. S Afr J Chem 68:115-125

Inyinbor AA, Adekola FA, Olatunji GA (2015b) EDTA modified Irvingia gabonensis: an efficient bioresource material for the removal of Rhodamine B. Pak J Anal Environ Chem $16(2): 38-45$

Inyinbor AA, Adekola FA, Olatunji GA (2016) Liquid phase adsorptions of Rhodamine $\mathrm{B}$ dye onto raw and chitosan supported mesoporous adsorbents: isotherms and kinetics studies. Appl Water Sci 1-11. doi:10.1007/s13201-016-0405-4, http://link.springer.com/article/10.1007/s13201-016-0405-4

Inyinbor AA, Adekola FA, Olatunji GA (2016b) Kinetic and thermodynamic modeling of liquid phase adsorption of Rhodamine B dye onto Raphia hookerie fruit epicarp. Water Resour Ind 15:14-27

Khan TA, Dahiya S, Ali I (2012) Use of kaolinite as adsorbent: equilibrium, dynamics and thermodynamic studies on the adsorption of Rhodamine B from aqueous solution. Appl Clay Sci 69:58-66

Khan TA, Nazir M, Khan EA (2013) Adsorptive removal of rhodamine B from textile wastewater using water chestnut (Trapa natans L.) peel: adsorption dynamics and kinetic studies. Toxicol Environ Chem 95(6):919-931 
Khan TA, Sharma S, Khan EA, Mukhlif AA (2014a) Removal of congo red and basic violet 1 by chir pine (Pinus roxburghii) sawdust, a saw mill waste: batch and column studies. Toxicol Environ Chem 96(4):555-568

Khan TA, Rahman R, Ali I, Khan EA, Mukhlif AA (2014b) Removal of malachite green from aqueous solution using waste pea shells as low-cost adsorbent adsorption isotherms and dynamics. Toxicol Environ Chem. doi:10.1080/02772248. 2014.969268

Khan TA, Khan EA, Shahjahan (2015) Removal of basic dyes from aqueous solution by adsorption onto binary iron-manganese oxide coated kaolinite: non-linear isotherm and kinetics modeling. Appl Clay Sci 107:70-77

Lagergren S, Svenska BK (1898) On the theory of so-called adsorption of materials, $R$. Swed Acad Sci Doc 24:1-13

Langmuir I (1916) The constitutional and fundamental properties of solids and liquids. J Am Chem Soc 38:2221-2295

Li L, Liu S, Zhu T (2010) Application of activated carbon derived from scrap tires for adsorption of Rhodamine B. J Environ Sci 22(8):1273-1280

Ma L, Xi Y, He H, Ayoko GA, Zhu R, Zhu J (2016) Efficiency of Femontmorillonite on the removal of Rhodamine $\mathrm{B}$ and hexavalent chromium from aqueous solution. Appl Clay Sci 120:9-15

Maneerung T, Liew J, Dai Y, Kawi S, Chong C, Wang C (2016) Activated carbon derived from carbon residue from biomass gasification and its application for dye adsorption: kinetics, isotherms and thermodynamic studies. Bioresour Technol 200:350-359

Miretzky P, Cirelli AF (2010) $\mathrm{Cr}(\mathrm{VI})$ and $\mathrm{Cr}(\mathrm{III})$ removal from aqueous solution by raw and modified lignocellulosic materials: a review. J Hazard Mater 180:1-19

Mittal H, Mishra SB (2014) Gum ghatti and $\mathrm{Fe}_{3} \mathrm{O}_{4}$ magnetic nanoparticles based nanocomposites for the effective adsorption of rhodamine B. Carbohydr Polym 101:1255-1264
Omorogie MO, Babalola JO, Unuabonah EI, Song W, Gong JR (2012) Efficient chromium abstraction from aqueous solution using a low-cost biosorbent: nauclea diderrichii seed biomass waste. J Saudi Chem Soc. doi:10.1016/j.jscs.2012.09.017

Pirbazari AE, Saberikhah E, HabibzadehKozani SS (2014) $\mathrm{Fe}_{3} \mathrm{O}_{4}-$ wheat straw: preparation, characterization and its application for methylene blue adsorption. Water Resour Ind 7-8:23-37

Rego B, Ferreira V (2001) Combined studies involving photonic and electronic spectroscopies. Adv surf Sci 38:327

Santos S, Ungureanu G, Boaventura R, Botelho C (2015) Selenium contaminated waters: an overview of analytical methods, treatment options and recent advances in sorption methods. Sci Total Environ 521-522:246-260

Stuart B (2004) Infrared spectroscopy: fundamentals and applications. Wiley, New Jersey. ISBNs: 0-470-85427-8 (HB); 0-470-85428-6 (PB)

Sulistina DR, Ratnawati R, Wiyasa IA (2014) Rhodamine B increases hypothalamic cell apoptosis and disrupts hormonal balance in rats. Asian Pac J Reprod 3(3):180-183

Temkin MI, Pyzhev V (1940) Kinetics of ammonia synthesis on promoted iron catalyst. Acta Physiochimica USSR 12:327-356

Wang XJ, Wang Y, Wang X, Liu M, Xia SQ, Yin DQ, Zhang YL, Zhao JF (2011) Microwave-assisted preparation of bamboo charcoal-based iron containing adsorbents for $\mathrm{Cr}(\mathrm{VI})$ removal. Chem Eng J 174:326-332

Wang G, Zhang S, Yao P, Chen Y, Xu X, Li T, Gong G (2015) Removal of $\mathrm{Pb}(\mathrm{II})$ from aqueous solutions by Phytolacca americana L. biomass as a low cost biosorbent. Arab J Chem. doi:10.1016/j.arabjc.2015.06.011

Weber WJ, Morris JC (1963) Kinetics of adsorption on carbon from solution. J Sanit Eng Division Am Soc Civ Eng 89:31-59

Zhang Z, Ian MO, Geoff AK, William OSD (2013) Comparative study on adsorption of two cationic dyes by milled sugarcane baggase. Ind Crops Prod 42:41-49 